\title{
Digital ulcers predict a worse disease course in patients with systemic sclerosis
}

\author{
Carina Mihai, ${ }^{1}$ Robert Landewé, ${ }^{2}$ Désirée van der Heijde, ${ }^{3}$ Ulrich A Walker, ${ }^{4}$ \\ Paul I Constantin, ${ }^{1}$ Ana Maria Gherghe, ${ }^{1}$ Ruxandra Ionescu, ${ }^{5}$ Simona Rednic, ${ }^{6}$ \\ Yannick Allanore, ${ }^{7}$ Jérôme Avouac, ${ }^{7}$ László Czirják, $^{8}$ Eric Hachulla, ${ }^{9}$ \\ Gabriela Riemekasten, ${ }^{10}$ Franco Cozzi, ${ }^{11}$ Paolo Airò, ${ }^{12}$ Maurizio Cutolo, ${ }^{13}$ \\ Ulf Mueller-Ladner, ${ }^{14}$ Marco Matucci-Cerinic, ${ }^{15}$ EUSTAR co-authors
}

\begin{abstract}
Handling editor Tore K Kvien
For numbered affiliations see end of article.

\section{Correspondence to}

Dr Carina Mihai, Department of Internal Medicine and Rheumatology, Cantacuzino Hospital, Carol Davila University of Medicine and Pharmacy, Bucharest, Ion Movilă str. 5-7, Bucharest 020475, Romania; carinamihai@gmail.com
\end{abstract}

Received 10 May 2014 Revised 4 November 2014 Accepted 25 January 2015 Published Online First 16 February 2015

\section{CrossMark}

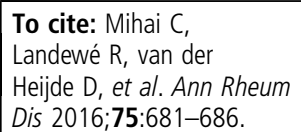

\section{ABSTRACT}

Objective Systemic sclerosis (SSC) is a systemic autoimmune disease with high morbidity and significant mortality. There is a great need of predictors that would allow risk stratification of patients with SSC and ultimately initiation of treatment early enough to ensure optimal clinical results. In this study, we evaluated whether a history of digital ulcers (HDU) at presentation may be a predictor of vascular outcomes and of overall clinical worsening and death in patients with SSC.

Methods Patients from the EULAR Scleroderma Trials and Research (EUSTAR) database, satisfying at inclusion the 1980 American College of Rheumatology classification criteria for SSc, who had a follow-up of at least 3 years since baseline or who have died, were included in the analysis. HDU at presentation as a predictor of disease worsening or death was evaluated by Cox proportional hazards regression analysis.

Results 3196 patients matched the inclusion criteria (male sex 13.2\%, 33.4\% diffuse subset). At presentation, 1092/3196 patients had an HDU (34.1\%). In multivariable analysis adjusting for age, gender and all parameters considered potentially significant, HDU was predictive for the presence of active digital ulcers (DUs) at prospective visits (HR $(95 \% \mathrm{CI})$ ): 2.41 (1.91 to 3.03), $p<0.001$, for an elevated systolic pulmonary arterial pressure on heart ultrasound (US-PAPs): 1.36 (1.03 to 1.80), $p=0.032$, for any cardiovascular event (new DUs, elevated US-PAPs or LV failure): 3.56 (2.26 to 5.62), $p<0.001$, and for death (1.53 (1.16 to 2.02), $p=0.003)$. Conclusions In patients with SSC, HDU at presentation predicts the occurrence of DUs at follow-up and is associated with cardiovascular worsening and decreased survival.

\section{INTRODUCTION}

Systemic sclerosis (SSc) is characterised by skin and internal organ fibrosis, in association with small vessel dysfunction and obliterative changes. While fibrosis is the hallmark of SSc, growing evidence supports the role of the microvasculopathy as the primary pathogenetic event. ${ }^{1}$ It has been shown that SSc is the connective tissue disease with the highest mortality. ${ }^{2}$ In fact, patients with SSc are at risk for developing life-threatening internal organ involvement such as interstitial lung disease (ILD), pulmonary hypertension, heart failure, severe gastrointestinal involvement and scleroderma renal crisis. ${ }^{3}$ Therefore, it is imperative to diagnose and to treat the disease and the involvement of internal organs as early as possible. However, in clinical practice this is a difficult task, in particular because reliable predictors or biomarkers of outcome are still missing. At present, the main strategy is to screen regularly for internal organ involvement, with a frequency that has not been standardised yet. Early aggressive treatment may be of crucial importance, but because of toxicity it is currently restricted to patients in whom clinically significant visceral involvement, in most cases with irreversible damage, has already been documented. For this reason, in SSc, there is an urgent need to identify and validate predictors of disease worsening.

Digital ulcers (DUs) occur rather early in the course of $\mathrm{SSc}^{4} 5$ and are a good candidate as clinical predictor of disease evolution. In SSc, several cross-sectional studies have found an association between the presence of DUs and more severe disease, as defined by the following: more extensive skin involvement in the SSc diffuse cutaneous subset (dc-SSc), ${ }^{4} 6 \quad 7$ the presence of pulmonary arterial hypertension, ${ }^{7}$ and of ILD. ${ }^{6}{ }^{8}$ Another prospective study showed that patients with SSc with DUs developed organ involvement approximately 2-3 years earlier than patients without DUs. Recently, it has been shown that DUs may herald internal organ involvement also in patients with very early SSc. ${ }^{5}$

These interesting results need to be confirmed in larger cohorts. The EULAR Scleroderma Trials and Research (EUSTAR) cohort is currently the largest prospective SSc cohort in the world. ${ }^{9}{ }^{10}$ The aim of the present work was to use the EUSTAR database to test the hypothesis that a history of DUs (HDU) at the patient's first presentation may predict a worse prognosis characterised by a worse disease course and death.

\section{METHODS}

All patients satisfying at inclusion the 1980 American Rheumatology Association classification criteria for $\mathrm{SSc}^{11}$ and with a follow-up of at least 3 years since inclusion, or who died (the baseline visit being registered before 1 January 2009), were extracted from the EUSTAR database. The following outcomes have been defined as indicating a severe course of the disease: active DUs observed at 
prospective visits; recent DUs, defined as DUs reported by the patient at prospective visits as having occurred since the last visit; skin involvement worsening, defined as an increase of the modified Rodnan skin score (mRSS) ${ }^{12}$ with at least five points and at least $20 \%$ compared with baseline; severe ILD, defined by a forced vital capacity (FVC) $<50 \%$ of the predicted value, at any visit; severely decreased alveolo-capillary diffusion of carbon monoxide (DLCO) of any cause, defined as a DLCO $<40 \%$ of the predicted value, at any visit; elevated systolic pulmonary arterial pressure $>40 \mathrm{~mm} \mathrm{Hg}$ as assessed by power Doppler heart ultrasound examination (US-PAPs), at any visit; heart failure, defined by an LVEF $<50 \%$, at any visit; scleroderma renal crisis (excluding the patients in which there is a history of SSc renal crisis at baseline); and overall cardiovascular events, defined as the occurrence of any of the following: recent DUs (as already specified), US-PAPs $>40 \mathrm{~mm} \mathrm{Hg}$ or LVEF $<50 \%$. All cause-mortality has also been investigated as an outcome.

\section{Statistical analysis}

The analysis was carried out with the statistics softwares IBM SPSS V.20.0 and SAS V.9.2. A p value $<0.05$ was considered as statistically significant. Comparisons between groups were performed with the $\chi^{2}$ test (for categorical variables) or with the independent samples t test (for numeric variables).

HDU at presentation and all baseline parameters recorded in the EUSTAR minimal, essential data set (MEDS), potentially influencing each of the outcomes described above, were evaluated by Kaplan-Meier survival plots and by age-adjusted and gender-adjusted Cox proportional hazards regression analysis (as categorical, dichotomous variables). Further, HDU at inclusion, age, gender and all baseline MEDS parameters considered potentially significant predictors were introduced in the multivariable analysis.

\section{RESULTS}

Following the inclusion criteria, 3207 patients were selected from the EUSTAR database. Of these, we had baseline data about the presence or absence of HDU in 3196 patients, of which 1092 (34.1\%) were positive for HDU. The demographic and clinical features of the study cohort are shown in table 1 .

The follow-up for the entire cohort was 5.0 2.2 years and 451 deaths of all causes were recorded up to February 2012. The time to death since the onset of Raynaud's phenomenon (RP) was $17.3 \pm 11.3$ years and since the first non-Raynaud symptom $8.9 \pm 8.6$ years. Death due to SSc was mentioned in 288 cases, non-SSc related death-in 85 cases while 78 deaths remained unclassified.

Patients with HDU at baseline (HDU-positive) were further compared by $\chi^{2}$ test with patients negative for HDU at inclusion (HDU-negative) in regard to baseline variables as well as to outcomes (table 1). HDU-positive patients had a significantly more frequent occurrence of both active DUs and recent DUs at prospective visits, as defined in the Methods section. Also, deterioration of FVC, DLCO and LVEF, as well as elevated US-PAPs, overall cardiovascular events, and death, were more frequent outcomes in HDU-positive patients. There was no difference in occurrence of skin involvement worsening and of scleroderma renal crisis between groups.

\section{Cox proportional hazards analysis of HDU as a predictor of the selected outcomes, adjusted for age and gender}

In age-adjusted and gender-adjusted analysis, HDU at inclusion in the cohort was predictive for both active and recent DUs at prospective visits (table 2), also for elevated US-PAPs, overall cardiovascular events and death of all causes (tables 3-5). We have not explored pulmonary arterial hypertension defined by right heart catheterisation as an outcome, because of the small number of patients who had performed this investigation (96 of

Table 1 Demographic data and outcomes in patients with and without a history of digital ulcers (DUs) at inclusion ( $n=3196$ )

\begin{tabular}{|c|c|c|c|c|}
\hline Demographic data & HDU+ $(n=1092)$ & HDU $-(n=2104)$ & All patients $(n=3196)$ & p Value* \\
\hline Female sex & $83.8 \%$ & $88.3 \%$ & $86.8 \%$ & 0.002 \\
\hline Age (years), mean $\pm S D$ & $52.5 \pm 14.0$ & $55.6 \pm 13.2$ & $54.6 \pm 13.6$ & $<0.001$ \\
\hline \multicolumn{5}{|l|}{ Disease duration (years) } \\
\hline Since first non-Raynaud symptom, mean \pm SD & $8.8 \pm 8.0$ & $7.7 \pm 7.4$ & $8.1 \pm 7.7$ & $<0.001$ \\
\hline Since onset of Raynaud's, mean \pm SD & $12.4 \pm 11.0$ & $12.2 \pm 11.3$ & $12.3 \pm 11.2$ & 0.564 \\
\hline Diffuse cutaneous subset & $41.7 \%$ & $29.1 \%$ & $33.4 \%$ & $<0.001$ \\
\hline Anti-centromere positive & $28.0 \%$ & $38.0 \%$ & $34.6 \%$ & $<0.001$ \\
\hline Anti-topoisomerase I positive & $42.4 \%$ & $28.9 \%$ & $33.5 \%$ & $<0.001$ \\
\hline Raynaud's phenomenon present & $98.2 \%$ & $95.7 \%$ & $96.5 \%$ & $<0.001$ \\
\hline \multicolumn{5}{|l|}{ Outcomes } \\
\hline DUs reported since last visit & $77.2 \%$ & $34.1 \%$ & $48.3 \%$ & $<0.001$ \\
\hline Active DUs at prospective visits & $34.6 \%$ & $14.0 \%$ & $20.6 \%$ & $<0.001$ \\
\hline Skin involvement worsening & $40.1 \%$ & $41.5 \%$ & $41.0 \%$ & 0.508 \\
\hline FVC $<50 \%$ predicted & $5.4 \%$ & $3.0 \%$ & $3.8 \%$ & 0.004 \\
\hline DLCO $<40 \%$ predicted & $20.1 \%$ & $15.4 \%$ & $17.0 \%$ & 0.001 \\
\hline LVEF $<50 \%$ & $5.5 \%$ & $3.6 \%$ & $4.2 \%$ & 0.073 \\
\hline Elevated US-PAPs & $39.7 \%$ & $34.5 \%$ & $36.2 \%$ & 0.004 \\
\hline Scleroderma renal crisis & $1.7 \%$ & $1.6 \%$ & $1.6 \%$ & 0.887 \\
\hline Death & $19.7 \%$ & $11.4 \%$ & $14.1 \%$ & $<0.001$ \\
\hline \multicolumn{5}{|c|}{$\begin{array}{l}\text { See the Methods section for definition of outcomes. } \\
\text { HDU+/HDU-, patients positive/negative for a history of DUs at baseline. } \\
\text { FVC }<50 \% \text { predicted, lung forced vital capacity }<50 \% \text { of the predicted value; DLCO }<40 \% \text { predicted, lung CO diffusion }<40 \% \text { of the predicted value; Elevated US-PAPs, a systolic } \\
\text { pulmonary arterial pressure }>40 \mathrm{~mm} \mathrm{Hg} \text { as measured by power Doppler heart ultrasound examination. For all these parameters values are considered at any visit including baseline. } \\
\text { *Significance of the difference between HDU+ and HDU- patients, by } \chi^{2} \text { test (for categorical variables) or independent samples t test (for numeric variables). }\end{array}$} \\
\hline
\end{tabular}


Table 2 Predictors of observed active digital ulcers (DUs) and of reported recent DUs (since previous visit) at prospective visits

\begin{tabular}{|c|c|c|c|c|c|c|c|c|}
\hline \multirow[b]{2}{*}{ Covariate (at baseline) } & \multicolumn{3}{|l|}{ Active DUs } & \multirow[b]{2}{*}{$\mathrm{p}$ Value } & \multicolumn{3}{|l|}{ Reported recent DUs } & \multirow[b]{2}{*}{$p$ Value } \\
\hline & $\begin{array}{l}\text { HR }(95 \% \mathrm{Cl}) \\
\text { Analysis adjusted } \\
\text { only for age and } \\
\text { gender }\end{array}$ & $p$ Value & $\begin{array}{l}\text { HR }(95 \% \mathrm{Cl}) \\
\text { Analysis adjusted for } \\
\text { age, gender and all } \\
\text { listed covariates }\end{array}$ & & $\begin{array}{l}\text { HR }(95 \% \mathrm{Cl}) \\
\text { Analysis adjusted } \\
\text { only for age and } \\
\text { gender }\end{array}$ & $p$ Value & $\begin{array}{l}\text { HR }(95 \% \mathrm{Cl}) \\
\text { Analysis adjusted for } \\
\text { age, gender and all } \\
\text { listed covariates }\end{array}$ & \\
\hline HDU & 2.60 (2.19 to 3.08$)$ & $<0.001$ & 2.41 (1.91 to 3.03$)$ & $<0.001$ & 3.59 (3.23 to 3.99$)$ & $<0.001$ & 3.23 (2.78 to 3.74$)$ & $<0.001$ \\
\hline Anti-topo I antibodies & 2.09 (1.76 to 2.48$)$ & $<0.001$ & 1.78 (1.39 to 2.28$)$ & $<0.001$ & 1.81 (1.62 to 2.01$)$ & $<0.001$ & 1.41 (1.20 to 1.66$)$ & $<0.001$ \\
\hline Joint contractures & 2.15 (1.81 to 2.56$)$ & $<0.001$ & 1.53 (1.20 to 1.94$)$ & $<0.001$ & 2.04 (1.83 to 2.27 ) & $<0.001$ & 1.38 (1.18 to 1.61$)$ & $<0.001$ \\
\hline Elevated US-PAPs & 1.52 (1.22 to 1.86$)$ & $<0.001$ & 1.37 (1.05 to 1.81$)$ & 0.023 & $1.49(1.30$ to 1.70$)$ & $<0.001$ & 1.41 (1.17 to 1.69 ) & $<0.001$ \\
\hline DLCO $<80 \%$ predicted & 1.61 (1.26 to 2.06$)$ & $<0.001$ & 1.29 (1.00 to 1.66$)$ & 0.055 & 1.66 (1.48 to 1.85$)$ & $<0.001$ & 1.08 (0.92 to 1.27$)$ & 0.349 \\
\hline Diffuse cutaneous subset & 1.65 (1.38 to 1.97$)$ & $<0.001$ & 1.15 (0.89 to 1.49$)$ & 0.282 & 1.61 (1.26 to 2.06$)$ & $<0.001$ & $1.22(1.02$ to 1.44$)$ & 0.024 \\
\hline
\end{tabular}

Bold typeface highlights the baseline covariate of interest, HDU.

Cox proportional hazards analysis adjusted only for age and gender (left column for each outcome) and for age, gender and all clinically important covariates (right column for each outcome).

DLCO, lung CO diffusion; Elevated US-PAPs, a systolic pulmonary arterial pressure $>40 \mathrm{~mm} \mathrm{Hg}$ as measured by power Doppler heart ultrasound examinationl; HDU, history of digital ulcers at baseline.

3196). Figure 1 illustrates by Kaplan-Meier survival plots the relationship between HDU at presentation and these outcomes.

Furthermore, HDU at baseline was found to be predictive for severe ILD with an HR and 95\% CI of 1.71 (1.13 to 2.59), $\mathrm{p}=0.011$ and for severely decreased DLCO with an HR $(95 \%$ CI) of 1.42 (1.19 to 1.70$), p<0.001$. HDU was not predictive for worsening of skin involvement, scleroderma renal crisis and cardiac worsening defined as an LVEF of $<50 \%$. In all models, both adjusting for disease duration since first non-Raynaud's symptom, or since RP onset, instead of age, led to similar results (data not shown).

\section{Cox proportional hazards analysis of HDU as a predictor of the selected outcomes, adjusted for age, gender and all clinically significant baseline covariates}

The results of the Cox proportional hazards regression analysis adjusted for age, gender and all potentially significant predictors of each outcome are shown in tables 2-5. HDU at baseline was predictive for active and for recent DUs, also for elevated US-PAPs, for overall cardiovascular events and for death. In this multivariable analysis, the relationship between HDU at baseline and the outcomes 'severe ILD' and 'severely decreased DLCO' was not statistically significant.

\section{DISCUSSION}

Our data, derived from the largest prospective SSc cohort, show that patients with HDU are prone to develop not only more new DUs, but an elevated US-PAPs and overall cardiovascular events as well, and are characterised by a decreased survival.

As expected, HDU at the first visit was found to be the strongest predictor for the occurrence/reoccurrence of DUs at prospective visits, with the highest $\mathrm{HR}$ among all covariates in the multivariable Cox proportional hazards models. We have been able to include as covariates several other baseline parameters that have been shown in other studies to be predictive for DUs, such as male gender, dcSSc subset, elevated US-PAPs, and antitopoisomerase I antibodies (ATA), thus demonstrating that HDU is a stronger predictor for new DUs than any other of these. ${ }^{67}$ Recently, biomarkers such as increased serum placental growth factor (PIGF) levels and low circulating endothelial progenitor cells (EPCs) levels have been shown to predict the subsequent development of DUs in patients with SSc. ${ }^{13}$ Noteworthy, in the multivariable model which also included high PlGF, low EPCs and high erythrocyte sedimentation rate (ESR) as independent predictors of new DUs, HDU was the predictor with the highest HR. ${ }^{13}$ The results of our multivariable analysis confirm once more that for clinical trials aiming at DU prevention, HDU is the

Table 3 Predictors of elevated pulmonary arterial pressure of all causes, estimated by power Doppler heart ultrasound examination (systolic pulmonary arterial pressure $>40 \mathrm{~mm} \mathrm{Hg}$ )

\begin{tabular}{|c|c|c|c|c|}
\hline Covariate (at baseline) & $\begin{array}{l}\text { HR }(95 \% \mathrm{Cl}) \\
\text { Analysis adjusted only } \\
\text { for age and gender }\end{array}$ & p Value & $\begin{array}{l}\text { HR }(95 \% \mathrm{CI}) \\
\text { Analysis adjusted } \\
\text { for age, gender and } \\
\text { all listed covariates }\end{array}$ & p Value \\
\hline HDU & 1.32 (1.17 to 1.49$)$ & $<0.001$ & $1.36(1.03$ to 1.80$)$ & 0.032 \\
\hline Dyspnoea (clinically significant) & 2.19 (1.25 to 2.47$)$ & $<0.001$ & 1.85 (1.32 to 2.58$)$ & $<0.001$ \\
\hline Lung function restrictive defect & 2.19 (1.95 to 2.47$)$ & $<0.001$ & 1.89 (1.38 to 2.60$)$ & $<0.001$ \\
\hline DLCO $<80 \%$ predicted & $2.08(1.72$ to 2.53$)$ & $<0.001$ & 1.88 (1.32 to 2.66$)$ & $<0.001$ \\
\hline Diastolic heart dysfunction & 1.63 (1.42 to 1.88$)$ & $<0.001$ & 1.47 (1.07 to 2.03$)$ & 0.018 \\
\hline Lung fibrosis (X-ray or HRCT) & 2.03 (1.80 to 2.28$)$ & $<0.001$ & 1.27 (0.93 to 1.74$)$ & 0.138 \\
\hline Anti-topo I antibodies & $1.43(1.24$ to 1.58$)$ & $<0.001$ & $1.11(0.82$ to 1.51$)$ & 0.509 \\
\hline Diffuse cutaneous subset & 1.40 (1.24 to 1.58$)$ & $<0.001$ & 0.88 (0.64 to 1.21$)$ & 0.432 \\
\hline
\end{tabular}


Table 4 Predictors of overall cardiovascular events, defined as a composite outcome resulting of the occurrence of any of the following: reported HDU occurring after any previous visit, systolic pulmonary arterial pressure $>40 \mathrm{~mm} \mathrm{Hg}$ by power Doppler heart ultrasound, or an $\mathrm{LVEF}<50 \%$

\begin{tabular}{|c|c|c|c|c|}
\hline Covariate (at baseline) & $\begin{array}{l}\text { HR }(95 \% \mathrm{CI}) \\
\text { Analysis adjusted } \\
\text { only for age and gender }\end{array}$ & p Value & $\begin{array}{l}\text { HR }(95 \% \mathrm{Cl}) \\
\text { Analysis adjusted for age, } \\
\text { gender and all listed covariates }\end{array}$ & p Value \\
\hline HDU & $2.12(1.48$ to 3.03$)$ & $<0.001$ & $3.56(2.26$ to 5.62$)$ & $<0.001$ \\
\hline Joint contractures & 2.96 (2.09 to 4.20$)$ & $<0.001$ & $1.82(1.10$ to 3.00$)$ & 0.019 \\
\hline Dyspnoea (clinically significant) & $2.06(1.24$ to 3.41$)$ & 0.005 & $2.02(0.93$ to 4.38$)$ & 0.076 \\
\hline Diastolic heart dysfunction & $2.06(1.26$ to 3.39$)$ & 0.004 & $1.53(0.88$ to 2.65$)$ & 0.133 \\
\hline Lung function restrictive defect & 1.89 (1.25 to 2.84$)$ & 0.002 & $1.30(0.72$ to 2.35$)$ & 0.386 \\
\hline DLCO $<80 \%$ predicted & 1.42 (0.95 to 2.12$)$ & 0.085 & 1.64 (1.04 to 2.58$)$ & 0.033 \\
\hline Lung fibrosis (X-ray or HRCT) & $1.45(0.98$ to 2.15$)$ & 0.061 & $0.72(0.41$ to 1.25$)$ & 0.240 \\
\hline Anti-topo I antibodies & 1.56 (1.07 to 2.27$)$ & 0.021 & $1.34(0.77$ to 2.34$)$ & 0.302 \\
\hline Diffuse cutaneous subset & 1.89 (1.33 to 2.70$)$ & $<0.001$ & $1.08(0.62$ to 1.87$)$ & 0.791 \\
\hline
\end{tabular}

most important and the most easily evaluable inclusion criterion to define high risk of DUs during follow-up. Another conclusion is that HDU-positive patients would benefit of vasoactive treatment such as prostanoids and endothelin receptor blockers as prevention for DUs reoccurrence, especially in the cold season, while HDU-negative patients would have less benefit.

Our results also show that HDU is predictive for overall cardiovascular events including new DUs, elevated US-PAPs and decreased LVEF, thus highlighting the severe prognosis indicated by HDU. As recently shown by Bruni et al, ${ }^{5}$ DUs appear to be a sentinel sign for internal organ involvement and as such for a worse disease course even in very early SSc. These findings strengthen the concept of a vascular phenotype of SSc, encompassing peripheral vasculature and organ microcirculation involvement. ${ }^{13}$ It may seem surprising that in multivariable analysis HDU was not predictive for severely decreased DLCO, while being a predictor of elevated US-PAPs; the most likely explanation is that we have used a rather strict definition for the severely decreased DLCO $(<40 \%$ than predicted), while the definition for increased US-PAPs set a more lenient threshold for abnormal PAP.
Finally, our study found that HDU is an independent predictor of a poorer survival. There are several studies on predictors of death in patients with SSc, but only a single-centre cohort study found that DUs were associated with a poorer prognosis in terms of survival. ${ }^{14}$ Noteworthy, our model includes as independent covariates next to HDU the baseline parameters DLCO and proteinuria, demonstrated by Bryan et $a l^{15}$ to be, next to age, gender and ESR, the most important predictors on survival. ${ }^{16}$ The Bryan model was intended as a clinical tool to predict survival and therefore is as simple as possible, while our model was focused on HDU and therefore we included all the covariates that were potentially significant (on clinical judgement). Similarly, Tyndall et al analysed the mortality of patients with SSc in the EUSTAR cohort and identified the following independent risk factors for death: proteinuria, an elevated US-PAPs, FVC $<80 \%$ of normal, the presence of dyspnoea on exertion, a reduced DLCO, an elevated age at SSc onset and a high mRSS. The statistical analysis of this study used the same methods as in our present article, and although in univariable analysis a HDU at inclusion was associated with decreased survival (HR 1.61, $\mathrm{p}<0.001$ ), this was no longer

Table 5 Predictors of death of all causes

\begin{tabular}{|c|c|c|c|c|}
\hline Covariate (at baseline) & $\begin{array}{l}\text { HR }(95 \% \mathrm{Cl}) \\
\text { Analysis adjusted } \\
\text { only for age and gender }\end{array}$ & p Value & $\begin{array}{l}\text { HR }(95 \% \mathrm{Cl}) \\
\text { Analysis adjusted for } \\
\text { age, gender and } \\
\text { all listed covariates }\end{array}$ & p Value \\
\hline HDU & 2.02 (1.67 to 2.43 ) & $<0.001$ & 1.53 (1.16 to 2.02 ) & 0.003 \\
\hline Dyspnoea (clinically significant) & 3.25 (2.68 to 3.96$)$ & $<0.001$ & 1.59 (1.17 to 2.15$)$ & 0.003 \\
\hline Lung function restrictive defect & 3.39 (2.78 to 4.11$)$ & $<0.001$ & 1.59 (1.13 to 2.23$)$ & 0.008 \\
\hline DLCO $<80 \%$ predicted & $3.76(2.50$ to 5.65$)$ & $<0.001$ & 2.07 (1.31 to 3.28$)$ & 0.002 \\
\hline Elevated US-PAPs & 3.54 (2.92 to 4.30$)$ & $<0.001$ & 2.21 (1.65 to 2.96$)$ & $<0.001$ \\
\hline Diastolic heart dysfunction & 2.03 (1.65 to 2.51$)$ & $<0.001$ & 1.34 (1.00 to 1.79$)$ & 0.052 \\
\hline Lung fibrosis (X-ray or HRCT) & 2.69 (2.21 to 3.28$)$ & $<0.001$ & $0.92(0.65$ to 1.29$)$ & 0.612 \\
\hline Renal crisis history & $2.90(1.87$ to 4.50$)$ & $<0.001$ & $2.03(1.13$ to 3.65$)$ & 0.018 \\
\hline Proteinuria & 3.50 (2.69 to 4.54$)$ & $<0.001$ & 2.09 (1.44 to 3.04$)$ & $<0.001$ \\
\hline Diffuse cutaneous subset & 2.48 (2.05 to 3.00$)$ & $<0.001$ & 1.64 (1.19 to 2.25$)$ & 0.002 \\
\hline Anti-topo I antibodies & 2.19 (1.81 to 2.66$)$ & $<0.001$ & $1.26(0.93$ to 1.70$)$ & 0.139 \\
\hline
\end{tabular}



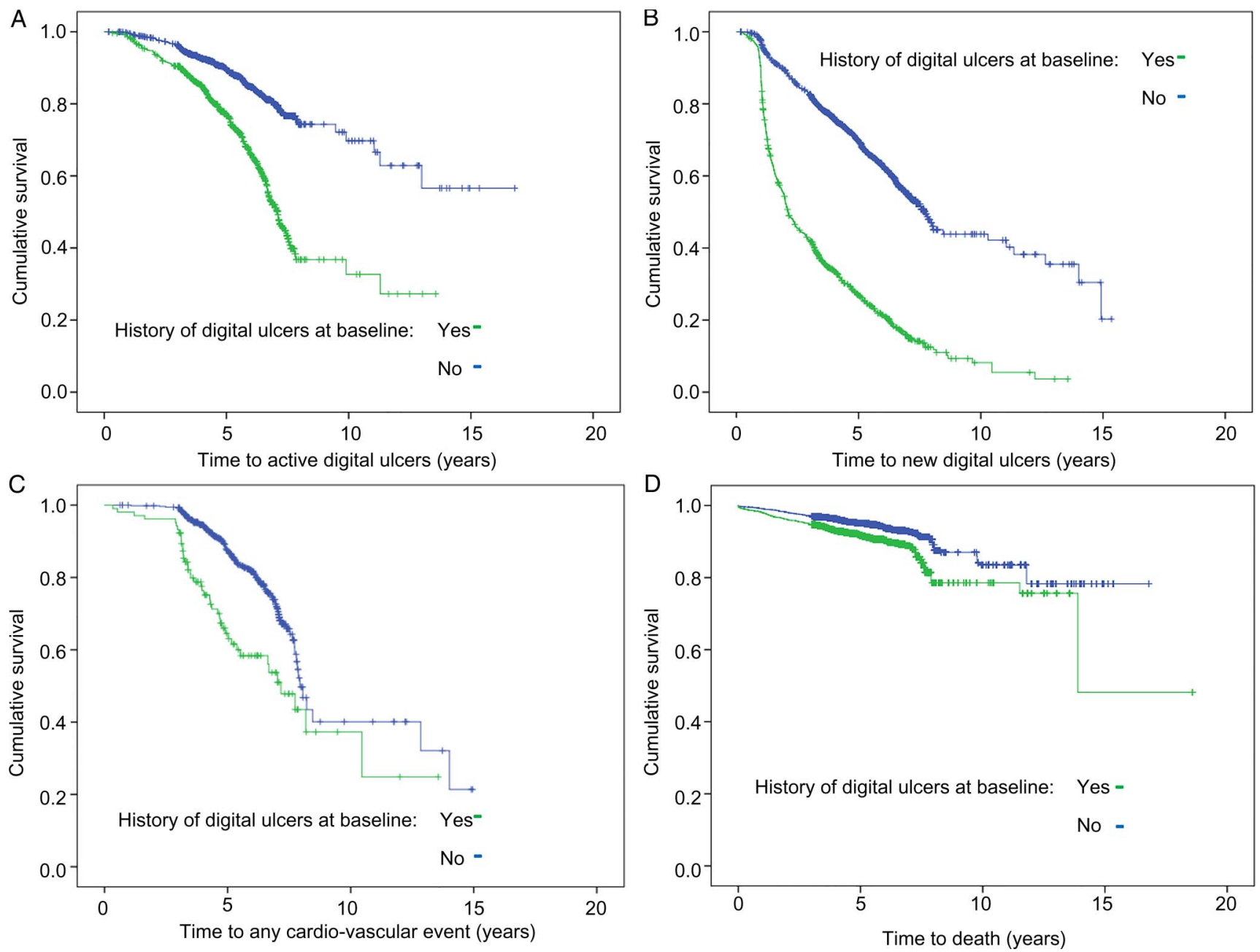

Figure 1 The influence of a history of digital ulcers (DUs) at presentation on several outcomes: (A) presence of active DUs at prospective visits; (B) reported recent DUs (since previous visit) at prospective visits; (C) overall cardiovascular events, defined as a composite outcome resulting of the occurrence of any of the following: reported history of DUs occurring after any previous visit, systolic pulmonary arterial pressure $>40 \mathrm{~mm} \mathrm{Hg}$ by power Doppler heart ultrasound, or an LVEF $<50 \%$; and (D) all-cause mortality ( $n=3196$ patients with SSc). Kaplan-Meier survival plots, all $p<0.001$ by the log-rank test.

significant in the multivariable model. ${ }^{10}$ However, it is not surprising that our study, with a larger population and a threefold longer follow-up, could identify more risk factors for death. Comparing the HRs of the various predictors of death in the multivariable model, it is of interest that an HDU has a prognostic value in regard to survival similar with that of dcSSc subset and of a decreased FVC and stronger than that of ATA.

The EUSTAR cohort is impressively large and there is no doubt that cohort studies have significant strengths: they can be used to study high-risk patients even before they develop certain manifestations, several outcomes can be studied for each exposure, and statistical modelling can be applied. But such cohorts also have limitations like missing data and loss to follow-up. ${ }^{17}$ In our study, for example, many missing values for baseline ESR ( $>50 \%$ of the patients) made us decide to not include ESR as a covariate in the Cox models.

Furthermore, in order to allow for a minimum of 3 years of follow-up, we have selected from the EUSTAR cohort only patients enrolled before 1 January 2009 and therefore the baseline data are derived from the original MEDS and not from MEDS online data. For this reason, as original MEDS include only few numerical variables (such as the mRSS and DLCO as a percentage of the predicted value), and do not record medication, we have not been able to define outcomes by a variation from baseline (with the exception of skin worsening), nor could we adjust for treatment. We have tried to overcome this issue by defining 'strong' outcomes that are independent of the baseline value of the respective parameter-for example, FVC $<50 \%$ of the predicted value, at any visit.

Another limitation is the fact that in the EUSTAR database the presence of 'baseline HDU' has been based on patientreported data only, and there is no distinct recording for different categories of DUs (ischaemic, traumatic or related to calcinosis). Recently, a clinical evidence-based classification of DUs has been proposed but our baseline data, recorded before 2009, are not detailed accordingly. ${ }^{18}$ Also, we would have found useful to include nailfold capillaroscopic pattern at baseline as a covariate in the multivariable models for new DUs, as it has been recently shown that a decreased capillary density is predictive for DUs, ${ }^{19}$ but for the majority of the patients baseline capillaroscopy data were not available.

In our cohort, average disease duration at baseline is over 8 years, showing that the majority of cases are not early. However, this is what we frequently encounter in clinical practice, so reported HDU remains an important item not to be forgotten in history taking, and useful in decision making in regard to treatment. 
The number of patients who developed US-PAPs $>40 \mathrm{~mm} \mathrm{Hg}$ or LV dysfunction was much lower than that of patients with recent or active DUs at prospective visits, and the multivariable Cox model on cardiovascular outcomes, including contractures as an independent covariate, suggests that new DUs are what this model mainly predicts. Further studies with more detailed baseline and follow-up data on cardiovascular outcomes are thus warranted to assess the predictive value of HDU for the development of cardiac and vascular complications.

The relationship between HDU at presentation and decreased survival, as suggested by our results, remains to be confirmed in studies with more detailed data on mortality. As we lacked information on the cause of death and this was not defined as SSc-related or non-SSc related in a large percentage of cases, we have not attempted to develop this analysis here.

In conclusion, our data demonstrate that in patients with SSc, $\mathrm{HDU}$ is a risk factor for more severe disease, predicting the occurrence of new DUs, new cardiovascular events and even a poorer survival. Reported HDU should prompt the physician to a careful clinical assessment, management and follow-up of the patient.

\section{Author affiliations}

${ }^{1}$ Department of Internal Medicine and Rheumatology, Cantacuzino Hospital, Carol Davila University of Medicine and Pharmacy, Bucharest, Romania

${ }^{2}$ Amsterdam Rheumatology Center/University of Amsterdam \& Atrium Medical Center, Heerlen, The Netherlands

${ }^{3}$ Leiden University Medical Center, Leiden, The Netherlands

${ }^{4}$ Basel University Hospital, Basel, Switzerland

${ }^{5}$ Department of Internal Medicine and Rheumatology, Sf. Maria Hospital, Carol

Davila University of Medicine and Pharmacy, Bucharest, Romania

${ }^{6}$ Rheumatology Clinic, luliu Hațieganu University of Medicine and Pharmacy, ClujNapoca, Romania

${ }^{7}$ Rheumatology A Department, Paris Descartes University, Cochin Hospital, Paris, France

${ }^{8}$ Department of Rheumatology and Immunology, University of Pecs, Pecs, Hungary

${ }^{9}$ Internal Medicine Department, Claude Huriez Hospital, Lille, France

${ }^{10}$ Department of Rheumatology, Charité University Hospital, Berlin, Germany

${ }^{11}$ Cattedra di Reumatologia, Dip. Medicina Clinica e Sperimentale, Policlinico, University of Padova, Padova, Italy

${ }^{12}$ Spedali Civili di Brescia, Rheumatology and Clinical Immunology Service, Brescia, Italy

${ }^{13}$ University of Genova, Research Laboratory and Academic Clinical Unit of Rheumatology, Genova, Italy

${ }^{14}$ Department of Rheumatology and Clinical Immunology, Giessen University, Bad Nauheim, Germany

${ }^{15}$ Division of Rheumatology AOUC \& Department of Experimental and Clinical

Medicine, Department of Biomedicine, University of Florence, Florence, Italy

Acknowledgements The authors and all EUSTAR centres are grateful for the support of the European League Against Rheumatism (EULAR).

Collaborators EUSTAR Co-authors: David Launay; Rucsandra Dobrotă; Roxana Sfrenț-Cornățeanu; Stefania Zingarelli; Erika Pigatto; Giovanna Cuomo; Paola Caramaschi; Lidia Ananieva; Susanne Ullman; Line Iversen; Alexandra Balbir Gurman; Yolanda Braun-Moscovici; Patricia E. Carreira; Beatriz E Joven; Tünde Minier; Serena Guiducci; Silvia Bellando-Randone; Raffaele Pellerito; Nicolas Hunzelmann; Ingo H. Tarner; Sebastião Cezar Radominski; Carolina de Souza Müller; Florenzo lannone; Jörg Henes; Dominique Farge Bancel; Nemanja Damjanov; Predrag Ostojić; Maria Rosa Pozzi; Roger Hesselstrand; Christopher Denton; Dorota Krasowska; Mohammed Tikly; Valeria Riccieri; Francesco Paolo Cantatore; Ada Corrado; José Antonio Pereira Da Silva; Maria João Salvador; Alan Tyndall; Armando Gabrielli; Oliver Distler; Suzan Jordan; Stefan Heitmann; Harald Burkhardt; Andrea Himsel; Blaz Rozman; Vanessa Smith; Filip De Keyser; Dusanka Martinovic Kalitena; Mislav Radic; lleana Filipescu; Ana Petcu; Panayiotis Vlachoyiannopoulos; Eugene J. Kucharz; Malgorzata Widuchowska; Magdalena Kopec-Medrek; Anna Kotulska; Gabriella Szücs; Aleksandra Stankovic; Bojana Stamenkovic; Carlo Francesco Selmi; Maria De Santis; Bianca Marasini; Bernard Coleiro; Vera Ortiz Santamaria; René Westhovens; Radim Bečvář; Srdan Novak; Merete Engelhart; Pierluigi Meroni; Francesca Ingegnoli; Silvana Zeni; Alberto Sulli; Jörg Distler; Sule Yavuz;
Carlomaurizio Montecucco; Kilian Eyerich; Brigitte Krummel-Lorenz; Thierry Zenone; Øyvind Midtvedt; Carlo Chizzolini; Matthias Seidel; Mara Oleszowsky; Maria Üprus; Daniela Opriş; Laura Groșeanu; Otylia Kowal Bielecka; Zea Mendoza Antonio; Jacek Szechinski; Jadranka Morović-Vergles; Raffaella Scorza; Francesco Puppo; Alessandro Mathieu; Branimir Anic; Jiri Stork; Simon Stebbings; Murat Inanc; Paul Hasler; Carlos Alberto von Mühlen; Martin Aringer; Sergei Popa; Mengtao Li; Edoardo Rosato.

Contributors All authors contributed to one or more of the following aspects of the manuscript: conception and design, acquisition, analysis and interpretation of data, drafting and revising the article.

Funding EUSTAR is supported by EULAR.

Competing interests None.

Patient consent Obtained.

Ethics approval All contributing EUSTAR centres have obtained approval from their respective ethics committee for including a patient's data in the EUSTAR database after the patient has given written informed consent.

Provenance and peer review Not commissioned, externally peer reviewed.

\section{REFERENCES}

1 Matucci-Cerinic M, Kahaleh B, Wigley FM. Evidence that systemic sclerosis is a vascular disease. Arthritis Rheum 2013;65:1953-62.

2 Elhai M, Meune C, Avouac J, et al. Trends in mortality in patients with systemic sclerosis over 40 years: a systematic review and meta-analysis of cohort studies. Rheumatology 2012;51:1017-26.

3 Steen VD, Medsger TA, Jr. Severe organ involvement in systemic sclerosis with diffuse scleroderma. Arthritis Rheum 2000:43:2437-44.

4 Hachulla E, Clerson P, Launay D, et al. Natural history of ischemic digital ulcers in systemic sclerosis: single-center retrospective longitudinal study. J Rheumatol 2007:34:2423-30.

5 Bruni C, Guiducci S, Bellando-Randone $S$, et al. Digital ulcers as a "sentinel" sign for early internal organ involvement in very early systemic sclerosis. Rheumatology 2015;54:72-6.

6 Tiev KP, Diot E, Clerson P, et al. Clinical features of scleroderma patients with or without prior or current ischemic digital ulcers: post-hoc analysis of a nationwide multicenter cohort (ItinérAIR-Sclérodermie). J Rheumatol 2009;36:1470-6.

7 Sunderkötter C, Herrgott I, Bruckner C, et al. Comparison of patients with and without digital ulcers in systemic sclerosis: detection of possible risk factors. $\mathrm{Br} J$ Dermatol 2009;160:835-43.

8 Khimdas S, Harding S, Bonner A, et al. Associations with digital ulcers in a large cohort of systemic sclerosis: results from the Canadian Scleroderma Research Group registry. Arthritis Care Res 2011;63:142-9.

9 Walker UA, Tyndall A, Czirjak $L$, et al. Clinical risk assessment of organ manifestations in systemic sclerosis: a report from the EULAR Scleroderma Trials And Research group database. Ann Rheum Dis 2007;66:754-63.

10 Tyndall AJ, Bannert B, Vonk $M$, et al. Causes and risk factors for death in systemic sclerosis: a study from the EULAR Scleroderma Trials and Research (EUSTAR) database. Ann Rheum Dis 2010;69:1809-15.

11 [No authors listed]. Preliminary criteria for the classification of systemic sclerosis (scleroderma). Subcommittee for Scleroderma Criteria of the American Rheumatology Association Diagnostic and Therapeutic Criteria Committee. Arthritis Rheum 1980;23:581-90.

12 Clements PJ, Lachenbruch PA, Seibold JR, et al. Inter- and intra-observer variability of total skin thickness score (modified-Rodnan) in systemic sclerosis (SSC). J Rheumatol 1995;22:1281-5.

13 Avouac J, Meune C, Riaz B, et al. Angiogenic biomarkers predict the occurence of digital ulcers in systemic sclerosis. Ann Rheum Dis 2012;71:394-9.

14 Vettori S, Cuomo G, Abignano G, et al. [Survival and death causes in 251 systemic sclerosis patients from a single Italian center]. Reumatismo 2010;62:202-9.

15 Bryan C, Knight C, Black CM, et al. Prediction of five-year survival following presentation with scleroderma. Development of a simple model using three disease factors at first visit. Arthritis Rheum 1999;42:2660-5.

16 Fransen J, Popa-Diaconu D, Hesselstrand R, et al. Clinical prediction of 5-year survival in systemic sclerosis: validation of a simple prognostic model in EUSTAR centers. Ann Rheum Dis 2011;70:1788-92.

17 Matucci-Cerinic M, Steen V, Seibold J. Clinical trials in systemic sclerosis: lessons learned and outcomes. Arthritis Res Ther 2007;9(Suppl 2):S7.

18 Amanzi L, Braschi F, Fiori G, et al. Digital ulcers in scleroderma: staging, characteristics and sub-setting through observation of 1614 digital lesions. Rheumatology 2010;49:1374-82.

19 Smith V, De Keyser F, Pizzorni C, et al. Nailfold capillaroscopy for day-to-day clinical use: construction of a simple scoring modality as a clinical prognostic index for digital trophic lesions. Ann Rheum Dis 2011;70:180-3. 


\section{Digital ulcers predict a worse disease course in patients with systemic sclerosis}

Carina Mihai, Robert Landewé, Désirée van der Heijde, Ulrich A Walker, Paul I Constantin, Ana Maria Gherghe, Ruxandra lonescu, Simona Rednic, Yannick Allanore, Jérôme Avouac, László Czirják, Eric Hachulla, Gabriela Riemekasten, Franco Cozzi, Paolo Airò, Maurizio Cutolo, Ulf Mueller-Ladner, Marco Matucci-Cerinic and EUSTAR co-authors

Ann Rheum Dis 2016 75: 681-686 originally published online February 16,2015

doi: 10.1136/annrheumdis-2014-205897

Updated information and services can be found at:

http://ard.bmj.com/content/75/4/681

\section{These include:}

Supplementary Supplementary material can be found at:

Material http://ard.bmj.com/content/suppl/2016/06/27/annrheumdis-2014-2058 97.DC1.html

References This article cites 19 articles, 10 of which you can access for free at: http://ard.bmj.com/content/75/4/681\#BIBL

Email alerting Receive free email alerts when new articles cite this article. Sign up in the service box at the top right corner of the online article.

Collections

Articles on similar topics can be found in the following collections

ARD Lay summaries (73)

Connective tissue disease (4243)

Epidemiology (1362)

Clinical diagnostic tests (1279)

Immunology (including allergy) (5128)

Radiology (1112)

Radiology (diagnostics) (750)

\section{Notes}

To request permissions go to:

http://group.bmj.com/group/rights-licensing/permissions

To order reprints go to:

http://journals.bmj.com/cgi/reprintform

To subscribe to BMJ go to:

http://group.bmj.com/subscribe/ 